\title{
Review
}

\section{The Rationale for Exercise in the Management of Pain in Parkinson's Disease}

\author{
Natalie E. Allen ${ }^{1, *}$, Niamh Moloney ${ }^{1}$, Vanessa van Vliet and Colleen G. Canning \\ Clinical and Rehabilitation Sciences Research Group, Faculty of Health Sciences, The University of Sydney, \\ Sydney, Australia
}

\begin{abstract}
Pain is a distressing non-motor symptom experienced by up to $85 \%$ of people with Parkinson's disease (PD), yet it is often untreated. This pain is likely to be influenced by many factors, including the disease process, PD impairments as well as co-existing musculoskeletal and/or neuropathic pain conditions. Expert opinion recommends that exercise is included as one component of pain management programs; however, the effect of exercise on pain in this population is unclear. This review presents evidence describing the potential influence of exercise on the pain-related pathophysiological processes present in PD. Emerging evidence from both animal and human studies suggests that exercise might contribute to neuroplasticity and neurorestoration by increasing brain neurotrophic factors, synaptic strength and angiogenesis, as well as stimulating neurogenesis and improving metabolism and the immune response. These changes may be beneficial in improving the central processing of pain. There is also evidence that exercise can activate both the dopaminergic and non-dopaminergic pain inhibitory pathways, suggesting that exercise may help to modulate the experience of pain in PD. Whilst clinical data on the effects of exercise for pain relief in people with PD are scarce, and are urgently needed, preliminary guidelines are presented for exercise prescription for the management of central neuropathic, peripheral neuropathic and musculoskeletal pain in PD.
\end{abstract}

Keywords: Parkinson disease, exercise, pain, neuronal plasticity

\section{INTRODUCTION}

Parkinson's disease (PD) is a progressive neurodegenerative condition which is projected to affect approximately 9 million people worldwide by 2030 [1]. Traditionally, PD was believed to result from a pathological process involving dopaminergic pathways, with dysfunction in the cortico-basal ganglia-thalamocortical loop due to loss of dopaminergic neurons in the substantria nigra of the basal ganglia [2]. However, recent work provides evidence

\footnotetext{
${ }^{1}$ These authors contributed equally to this work.

*Correspondence to: Natalie E. Allen, Clinical and Rehabilitation Sciences Research Group, Faculty of Health Sciences, The University of Sydney, PO Box 170, Lidcombe, NSW 1825, Australia, Tel.: +61 29351 9016; Fax: +61 29351 9278; E-mail: natalie.allen@sydney.edu.au.
}

that degeneration begins in the dorsal motor nucleus of the vagal nerve and olfactory nucleus, followed by the lower brain stem, then the basal ganglia and forebrain and extending into the cortex $[2,3]$. This diffuse pathology means that both dopaminergic and nondopaminergic neural pathways are affected, resulting in numerous motor and non-motor impairments. The cardinal motor impairments of PD are bradykinesia (slowness of movement), rigidity (increased resistance to passive movement), tremor and postural instability [4]. Akinesia (absence of movement or freezing) and dystonia (prolonged abnormal postures) are also common motor impairments [5]. The nonmotor impairments are wide ranging and include cognitive and emotional impairments, autonomic dysfunction, sleep disorders and sensory abnormalities, including pain $[5,6]$. 
Pain is a distressing non-motor symptom experienced by up to $85 \%$ of people with PD [7]. After adjusting for osteo-articular comorbidities, people with PD are twice as likely to experience chronic pain as people without PD [8]. Pain in people with PD is associated with impaired sleep [9], depression $[8,10]$ and reduced quality of life [11-14]. Although pain is reported to be one of the most troubling symptoms experienced by people with PD, recognition and management of pain receives little attention in clinical practice $[7,8,15-17]$. This may be due to the complex nature of pain and its poorly understood neurophysiology, as well as the paucity of trials evaluating potential interventions to manage pain in PD. Consequently, current treatment and management of pain in people with PD is largely based on expert opinion and clinical experience. Medication, including dopaminergic agents and conventional analgesics, may help to reduce pain [15-18]. Additionally, exercise (i.e. intentional physical activity performed to improve health and fitness, including Physical Therapy [19]) is often recommended as one component of a pain management program [17, 20-23].

\section{Scope of this review}

This narrative review aims to explore the scientific rationale and evidence regarding the role for exercise in the management of pain in people with PD. The review begins by outlining a pain classification system as it relates to people with PD. This is followed by a review of the literature discussing how exercise may influence the neurophysiology of pain in PD, including the impact of exercise on neuroplasticity and neuro-restoration as well as on dopaminergic and non-dopaminergic pain inhibitory pathways. Following this, the evidence for the role of exercise in the clinical management of pain is described. Finally, considerations for the prescription of exercise to manage pain are discussed and a framework for prescribing exercise in the presence of pain is presented.

\section{THE CLASSIFICATION OF PAIN IN PARKINSON'S DISEASE}

A classification system for pain in PD initially proposed by Ford [17] and subsequently updated by Wasner and Deuschl [16] identifies the following pain types: central neuropathic pain, peripheral neuropathic pain, and nociceptive pain (includes musculoskeletal pain, dystonic pain, visceral pain and cutaneous pain). In this review, we will focus on the role of exercise as it relates to neuropathic pain (central and peripheral) and musculoskeletal pain; the clinical features of which are presented in Table 1.

Neuropathic pain is defined as pain arising from a lesion or a disease affecting the somatosensory system [24] and can arise from the central or peripheral nervous systems. Central neuropathic pain often manifests as tingling, burning or shooting pain, which is not confined to a nerve root or peripheral nerve and is not due to dystonia, rigidity or a musculoskeletal problem $[16,17]$. It is believed to be due to the disease process itself [17] and is estimated to affect approximately $10 \%$ of people with PD [15]. Peripheral neuropathic pain relates to pain arising from a radiculopathy or peripheral neuropathy $[16,17]$. This pain may be similar in nature to central neuropathic pain but tends to be confined to the distribution of a specific nerve or nerve root [25].

Musculoskeletal pain may arise from actual or threatened damage to muscles and joints. It is often aching in nature or sharp with movement and usually presents in the absence of burning or electric-shock like pain or paraesthesia [26]. There is usually clinical evidence of a clear anatomical or mechanical nature of aggravating and easing factors [26], which may be exacerbated by abnormal postures or excessive rigidity [17]. Pain may become chronic in people with PD in which case the relationship between aggravating factors and pain response becomes less predictable, while sensitisation of the nervous system becomes more pronounced. This can occur with any type of pain.

The pain experienced by people with PD can, therefore, be directly attributable to the disease process, sensitisation of the nervous system and to structural or biomechanical abnormalities, which may or may not be exacerbated by PD motor impairments. A comprehensive review of the pathophysiology of pain and different pain types in PD is beyond the scope of this paper but readers are directed to recent publications by Ford [17] and Wasner and Deuschl [16] for more detail.

\section{THE POTENTIAL INFLUENCE OF EXERCISE ON THE PATHOPHYSIOLOGY OF PAIN IN PD}

The influence of the neurodegenerative processes of PD on pain is not fully understood; however, there is some evidence that these processes could lead to impaired pain processing, potentially influencing the experience of pain in people with PD 
Table 1

Key clinical features of central and peripheral neuropathic pain and musculoskeletal pain

\begin{tabular}{|c|c|c|c|}
\hline & Central neuropathic pain & Peripheral neuropathic pain & Musculoskeletal pain \\
\hline Pain distribution & Diffuse & $\begin{array}{l}\text { Specific dermatomal or } \\
\text { cutaneous nerve distribution }\end{array}$ & $\begin{array}{l}\text { Localised to the area of } \\
\text { injury/dysfunction (may } \\
\text { include somatic referred pain) }\end{array}$ \\
\hline Pain symptoms & Aching, burning, cramping. & $\begin{array}{l}\text { Sharp, shooting, burning and/or } \\
\text { electric shock like pain, } \\
\text { paraesthesia/dysaesthesia }\end{array}$ & $\begin{array}{l}\text { Generally: } \\
\text { Sharp pain with movement, } \\
\text { ache/cramp at rest } \\
\text { Absence of paraesthesia, } \\
\text { dysaesthesia, electric shock } \\
\text { like pain. } \\
\text { In people with } \mathrm{PD}^{a} \text { : Pain may be } \\
\text { associated with dystonia } \\
\text { and/or rigidity }\end{array}$ \\
\hline Physical examination & $\begin{array}{l}\text { May present with diffuse } \\
\text { hyperalgesia and/or allodynia } \\
\text { (to touch, pressure or } \\
\text { heat/cold) }\end{array}$ & $\begin{array}{l}\text { Neurological deficit and/or } \\
\text { sensory hypersensitivity within } \\
\text { a neuroanatomical distribution }\end{array}$ & $\begin{array}{l}\text { Pain reproducible on standard } \\
\text { physical examination } \\
\text { Pain response to physical testing } \\
\text { predictable and proportionate } \\
\text { to degree of testing }\end{array}$ \\
\hline Investigations & $\begin{array}{l}\text { None specific for diagnosis of } \\
P D^{a} \text { - may be useful to exclude } \\
\text { peripheral neuropathic pain }\end{array}$ & $\begin{array}{l}\text { MRI or EMG/nerve conduction } \\
\text { studies }\end{array}$ & $\begin{array}{l}\text { Usually not warranted; } \\
\text { Radiology can be used to } \\
\text { exclude specific diagnoses }\end{array}$ \\
\hline $\begin{array}{l}\text { Reference for diagnostic } \\
\text { criteria }\end{array}$ & $\begin{array}{l}\text { IASP }{ }^{b} \text { criteria for classification } \\
\text { of neuropathic pain [25] and } \\
\text { Smart et al. [28] }\end{array}$ & $\begin{array}{l}\text { IASP }{ }^{b} \text { criteria for classification } \\
\text { of neuropathic pain [25] and } \\
\text { Smart et al. [28] }\end{array}$ & Smart et al. [28] \\
\hline
\end{tabular}

${ }^{a}$ PD: Parkinson's Disease; ${ }^{b}$ IASP: International Association for the Study of Pain.

$[15,17,21,27-29]$. The subsequent sections of this review will focus on the potential of exercise to influence two primary physiological processes in PD, namely the promotion of neuroplasticity and neurorestoration, and pain modulation via dopaminergic and non-dopaminergic pain inhibitory pathways. Although these processes are inter-related, for clarity of presentation, these processes and the influence of exercise on them will be presented separately.

\section{Neuroplasticity and neuro-restoration}

Emerging evidence suggests that exercise may promote neuroplasticity (i.e. the anatomical, physiological and functional re-organisation of the brain in response to changes in environment or behaviour) $[30,31]$ and neuro-restoration (i.e. regeneration of damaged nervous tissue) [31] in PD via mechanisms that may have the potential to improve processing of nociceptive signals. There is evidence from animal studies that exercise can promote neuroplasticity and neurorestoration by increasing brain neurotrophic factors, synaptic strength and angiogenesis as well as stimulating neurogenesis and improving metabolism and the immune response [31-34]. For example, people with PD have a loss of dendritic spines from striatal neurons $[35,36]$. Interestingly, in a rodent model of $\mathrm{PD}$, treadmill running resulted in a reversal of this dendritic spine loss [37]. Research with a rodent model of diabetes has also suggested that maladaptive dendritic spine remodelling may contribute to neuropathic pain in people with diabetes mellitus [38]. Therefore, the exercise-induced dendritic changes found in the rodent model of PD provide preliminary evidence that exercise could influence pain in people with $\mathrm{PD}$ via neuroplastic mechanisms. The facilitation of neuroplasticity by exercise in healthy and injured human brains has been well documented. [31, 34, 39-42]. Recent use of imaging has provided evidence that exercise can promote neuroplasticity in people with PD, with neuroplastic changes observed following treadmill walking/running [40] and balance exercises [42].

There is a small amount of evidence which suggests that exercise might be able to slow the progression of PD in humans. Progressive resistance exercise [43], partnered dancing [44] and high cadence cycling [45] have all resulted in improvements in motor impairments when participants were assessed OFF their PD medication. Additionally, one trial has utilised transcranial magnetic stimulation to assess the effects of eight weeks of moderate to vigorous intensity treadmill training on corticomotor excitability via measurement of the cortical silent period [46]. The cortical silent period is typically shortened in PD, suggesting higher levels of motor system excitability with competing motor networks interfering with the function 
of cortico-basal ganglia loops. Results showed a lengthening of the cortical silent period following exercise, suggesting improved intracortical inhibition and therefore, suppression of competing motor networks allowing enhanced functioning of cortico-basal ganglia loops, leading to improved mobility [46]. The length of time that these changes lasted following exercise is unknown.

It is unclear whether improvements in motor impairments and mobility following exercise are due to slowing of disease progression, or due to maximising abilities within the existing impaired system [47]. In the absence of easily administered and valid biomarkers for disease progression in PD [48], research utilising imaging techniques to examine neuroplasticity and neuro-restoration is required to determine if exercise can delay disease progression, and if any such delay can reduce pain symptoms in people with PD.

\section{Dopaminergic pain inhibitory pathways}

The basal ganglia receive nociceptive information (i.e. the neural encoding of noxious stimuli) from several sources within the cerebral cortex, thalamus and amygdala [29, 49]. The classic motor symptoms of PD (e.g. bradykinesia, tremor and rigidity) are widely attributed to the degeneration of dopamine producing cells within the substantia nigra of the basal ganglia $[50,51]$, which is accompanied by alterations in glutamatergic neurotransmission [31, 34, 52, 53]. Dopamine and glutamate are important neurotransmitters within the central nervous system. Dopamine is traditionally known for its role in motivation and reward; [54] however, it is also known to have an antinociceptive role, suppressing nociceptive signalling. Recent data provide evidence that dopamine can modulate pain and that it does so via the rostro-ventral medulla [55] and by inhibiting nociceptive signalling in the dorsal root ganglion [56].

Glutamate is the main excitatory neurotransmitter in the brain, and increased glutamatergic signalling has been linked to sensitization of the central nervous system, [57] potentially leading to hypersensitivity to noxious and non-noxious stimuli [58]. Studies utilising rodent models of PD suggest that exercise leads to an improvement in motor symptoms as a result of an improvement in dopamine transmission and a modulation in glutamate transmission [31, 32, 34]. Exercise, particularly treadmill running, has been shown to improve dopamine neurotransmission by improving the availability of dopamine [31, 34] as well as restoring dopamine D2 receptors in the dorsal striatum in a rodent model of PD [59]. Furthermore, a pilot trial of eight weeks of moderate to vigorous treadmill training in people with early denovo PD increased striatal dopamine $\mathrm{D} 2$ receptor binding potential, suggesting that exercise could produce improved dopamine transmission in humans as well as in animals [40]. This finding is particularly important as studies of healthy people and people experiencing chronic pain suggest that there is an association between pain perception and D2 receptor binding potential in the striatum [60]. Studies using animal models of PD also suggest that exercise may influence the availability and transmission of glutamate, which could contribute to improved basal ganglia function [31, 34, 61, 62]. Further work is needed to explore any effects of exercise on dopamine and glutamate transmission in people with $\mathrm{PD}$ and to determine if any exercise-mediated changes translate to a reduction in pain.

The extent to which the depletion of dopamine and the relative excess of glutamate within the basal ganglia contribute to pain in PD is unclear. However, given that at least some of the pain experienced by people with PD appears to be reduced by the use of dopaminergic medication [17, 20-22], along with the potential role of dopamine in pain inhibition, dopaminergic pathways seem like an appropriate target for pain management in PD. Nevertheless, what little data that does exist regarding the effectiveness of dopaminergic medication in pain management in PD is conflicting. Some studies have reported evidence for a reduction in pain sensitivity following dopaminergic medication $[63,64]$. In contrast, no impact, or in some individuals, a worsening of pain sensitivity following dopaminergic medication has also been reported [65-67]. While dopaminergic pathways may be potential targets for treatment of pain by exercise, given these results, the function of non-dopaminergic pain processing is also important to consider in PD.

\section{Non-dopaminergic pain inhibitory pathways}

As outlined in section 1, there is growing awareness that the pathology of PD extends beyond dopaminergic pathways. In fact, neurodegeneration in PD also affects the noradrenergic, serotonergic, cholinergic, and peptidergic systems, all of which are essential systems for pain processing and descending pain inhibition [29, 51]. It has been hypothesized that pain in PD is altered by the disease-related neuronal cell loss and Lewy body formation in the parabrachial region and the periaqueductal grey matter of the medial spinoreticulothalamic pain pathway, which is thought to influence affec- 
tive, cognitive and autonomic responses to pain [17, 68]. The effect of exercise on PD related pathologies of these non-dopaminergic structures and systems remains unclear.

In non-PD models, the most widely known mechanism for pain inhibition following exercise is mediated through the release of endogenous opioids [69]. This has been demonstrated in animal studies, with both short exercise bouts and extended or repeated bouts of exercise shown to induce analgesic effects via activation of the opioid system [70, 71]. More recently, pain inhibition has also been demonstrated in response to high intensity exercise, again in animals [72, 73]. Data from these latter studies identified that resulting anti-nociception from intensive exercise was due to adenosine expression in addition to opioid regulation [73], while activation of serotonergic receptors has also been implicated in pain inhibition [72, 73]. Serotonin is known to be involved in pain inhibition [74]; however, the role of adenosine is less well documented. Adenosine is released following the breakdown of adenosine triphosphate during exercise, resulting in increased extracellular adenosine [75, 76]. Adenosine has a role in the suppression of inflammation [77, 78], including inhibition of the expression of pro-inflammatory cytokines and increased expression of anti-inflammatory cytokines. Therefore, adenosine release following exercise may be an important player in pain inhibition in PD and the role of exercise in moderating pain via these mechanisms in $\mathrm{PD}$ warrants investigation.

Of further interest for those with PD suffering from peripheral neuropathic pain, pain inhibitory effects of aerobic exercise have been demonstrated in animals with induced peripheral neuropathic pain, with diminished sensory hypersensitivity evident following repeated exercise [79, 80]. In a study by Stagg et al. (2011), the analgesic effects observed following exercise were activated via opioidergic pathways, with successful reversal of anti-nociceptive effects following administration of opioid antagonists [79].

An interesting link between the motor cortex and pain inhibitory pathways has also been demonstrated in a number of animal models, whereby motor cortex stimulation has resulted in inhibition of thalamic sensory neurons and increased activation of the peri-aqueductal grey, an important area for the modulation of pain $[33,81]$. The peri-aqueductal grey is a key area for the integration of ascending nociceptive input from the spinal cord and inputs from various parts of the brain, such as the forebrain and diencephalon [82], the amygdala [83] and the hypothalamus [82], with subsequent activation of descending pain inhibition. Whether similar activation of pain inhibitory pathways can be exerted by motor cortex stimulation in humans and indeed, by exercise, is not known. However, the consistent data that exercise stimulates the release of endogenous opioids, a key effect of peri-aqueductal grey activation provides some support for this theory.

\section{DOES EXERCISE IMPROVE PAIN IN CLINICAL PRACTICE?}

It is now well established that exercise is beneficial for people with PD. It has been shown to be effective in improving mobility [84-86], balance [84, 86]; muscle strength [43, 87] and cardiovascular fitness [88-90], and there is some evidence that it may also reduce falls [85, 91-93]. Despite the theoretical evidence that exercise may be able to influence pain in people with $\mathrm{PD}$, there is a paucity of clinical trials exploring the effect of exercise on pain. Our search yielded only two studies which reported the effect of exercise on pain in people with PD $[94,95]$. It should be noted, however, that pain was not the main focus of the intervention or outcomes in either study. The first is a single group intervention study, which evaluated the effect of 12 weeks of group exercise on different domains of quality of life in 20 people with mild to moderate PD [95]. Exercise sessions were conducted three times per week and included flexibility, strength and aerobic exercise. This small uncontrolled trial did not show an improvement in pain scores as measured in the pain domain of the Nottingham Health Profile [96]. However, a non-significant $8 \%$ reduction in pain was reported.

The second study [94] was a randomized trial where 90 people with mild to moderate PD were randomized to one of three exercise interventions: flexibility and relaxation, walking or Nordic walking. Participants exercised three times per week for six months. Pain was rated using a visual analogue scale in order to monitor potential adverse events. Results showed a reduction in the number of participants reporting pain and the intensity of pain in the neck, hip and iliosacral joint reduced in all three groups. Additionally, the intensity of pain was reduced in the back, hands and legs of the walking and Nordic walking groups compared to the flexibility and relaxation group. Neither of these studies utilised a no exercise control group or considered pain classification, so the results do not indicate if the exercise reduces pain compared to no intervention, or if exercise is preferentially effective for one type of pain 
over another. Furthermore, these results do not rule out the possibility that some individuals may experience an increase in their pain following exercise. However, taken together, the results from these two studies suggest that the effect of exercise on pain warrants further investigation.

Exercise is commonly used in the management of acute and chronic musculoskeletal pain in the general population with demonstrated benefits in terms of pain reduction and improved function in people with pain arising from spinal structures and osteoarthritis. Musculoskeletal pain within the context of PD is thought to be due, in part, to rigidity, akinesia and dystonia $[16,18]$. The lack of mobility, stiffness and deformities of posture brought about by these impairments may give rise to aching, cramping and joint tenderness characteristic of the musculoskeletal pain experienced by people with PD [17]. This pain is common in the hips, knees, ankles and back [16]. Exercise therapy has demonstrated effects on musculoskeletal pain and disability in the general population with collated evidence indicating that exercise has application in the relief of both chronic neck [97, 98] and back pain [99]. Both tailored exercise involving strengthening and more general exercise, such as walking programs, are beneficial in the treatment of osteoarthritis, with pooled data demonstrating reductions in associated knee [100] and hip pain [101]. Such evidence suggests that exercise programs may be beneficial in the treatment of pain arising from the musculoskeletal system in people with $\mathrm{PD}$.

\section{CONSIDERATIONS FOR EXERCISE PRESCRIPTION IN PARKINSON'S DISEASE}

While specific exercise programs may be advantageous for some types of pain in PD, it is likely that general exercise prescription has a stronger scientific basis, particularly for chronic musculoskeletal pain and neuropathic pain. Most exercise protocols for chronic pain management advocate a 'quota based' exercise program where patients are required to progress exercises based on pre-planned increments from the patient's activity baselines, rather than focusing on pain responses during exercise [102]. Nevertheless, recent data suggest that symptom exacerbation during and following exercise should be given some consideration. In chronic pain conditions where the underlying pathophysiology relates to central sensitisation (e.g. fibromyalgia, chronic fatigue syndrome and whiplash associated disorder), impaired endogenous pain inhibition during and following exercise has been recorded [103-105]. An evidence-based approach to pain management in these cases has not been fully established; however, a multidisciplinary approach with a carefully graded approach to physical activity has been proposed [106]. It is not known whether analgesic responses to exercise are impaired in PD. Preliminary data suggest that pain sensitivity is increased in this cohort but not necessarily in response to conditioning stimuli i.e. conditioned pain modulation [107]; however, changes in pain sensitivity following exercise as a conditioning stimulus have yet to be investigated in PD.

As an extension to this consideration of increased pain sensitivity in response to exercise, it is worth noting that while exercise could decrease pain by stimulating the motor cortex, there is evidence in humans that pain may lead to decreased motor cortex excitability with a resulting detrimental effect on neuroplasticity [108, 109]. Therefore, although exercise can promote neuroplasticity and potentially reduce pain, it is yet to be determined if exercise which exacerbates pain, could prevent or impede desirable neuroplastic changes with the potential to promote pain modulation within the brain. As such, it would seem prudent to avoid acute exacerbations of pain in response to exercise, while allowing tolerance for physical activity to be developed.

\section{A framework for exercise prescription in $P D$}

This review has highlighted the lack of direct evidence for the efficacy of exercise in the management of pain in people with PD. However, given that current expert opinion recommends exercise for the management of pain, [17, 20-23] and that exercise is beneficial for improving the performance of physical activities in people with PD, [86] it seems likely that clinicians will be prescribing exercise programs for people with PD who experience significant pain. The following framework has therefore been designed to assist clinicians in making decisions regarding exercise for pain management in people with PD.

The approach to exercise prescription will vary according to the type and severity of pain, aggravating factors, presenting PD-specific motor and other non-motor impairments, as well as baseline levels of physical activity. The first step in planning exercise interventions for pain management is to consider the type of pain which a patient may be experiencing. Characteristics for each pain classification relevant for 
Central neuropathic pain

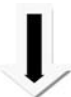

Pharmacological
Management
General exercise
Commence with graded
physical activity
rogress to aerobic exercise
Progress to high intensity
exercise where possible

Peripheral neuropathic pain

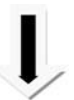

$$
\begin{gathered}
\text { Further investigations } \\
\text { /intervention as required } \\
\text { Specific exercise } \\
\text { To reduce compression of } \\
\text { nerve/nerve root } \\
\text { To reduce neural } \\
\text { mechanosensitivity (in stable } \\
\text { conditions only) } \\
\text { General exercise } \\
\text { Commence with graded } \\
\text { physical activity } \\
\text { Progress to aerobic exercise } \\
\text { Progress to high intensity } \\
\text { exercise where possible }
\end{gathered}
$$

\author{
Musculoskeletal pain \\ (acute/chronic)
}

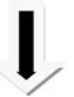

Further investigations
/intervention as required

Specific exercise

To target specific strength or

movement impairments

General exercise

Commence with graded

physical activity, if required

Progress to aerobic exercise

Progress to high intensity

aerobic exercise where possible

Fig. 1. Integration of exercise prescription for pain in Parkinson's disease.

Table 2

Principles of general exercise prescription for the management of pain in Parkinson's disease

- Patient centred, functional approach: identify patient goals and functional demands

- Patient education focussed on the neurophysiology of pain, reducing the threat value of physical activity, explaining the role of exercise in managing pain and improving physical function

- Careful identification of baseline levels of physical activity

- Quota based pacing with steady, measured progression

- Avoid overactivity/underactivity cycle

- Avoid acute pain exacerbation if possible

- Avoiding flare-ups may be unavoidable - develop a flare-up plan

- Coordinate pharmacological and other methods of pain

management with general exercise to facilitate optimal responses

Adapted from Butler and Moseley [110] \& Nicholas et al. [102].

people with PD are outlined in Table 1 (see Wasner and Deuschl (2012) [16] for more detail). A suggested framework for specific and general exercise prescription is also outlined in Fig. 1 with broad principles for general exercise prescription presented in Table 2.

\section{CONCLUSION}

This review presents the rationale for the use of exercise in the management of pain in PD. A number of classifications of pain have been identified as potentially important in PD and each may warrant different approaches to exercise prescription. The neurophysiological effects of exercise such as neuroplasticity, neuro-restoration and activation of dopaminergic and non-dopaminergic pain inhibition provide a sound biological rationale for employing exercise in pain management; however, clinical studies in a PD population are required to investigate this further.

\section{ACKNOWLEDGMENTS}

The authors would like to acknowledge A/Prof Toby Hall and Dr Jooeun Song for their reviews of the manuscript during preparation.

\section{CONFLICT OF INTEREST}

The authors have no conflict of interest to report.

\section{REFERENCES}

[1] Dorsey ER, Constantinescu R, Thompson JP, Biglan KM, Holloway RG, Kieburtz K, Marshall FJ, Ravina BM, Schifitto G, Siderowf A, \& Tanner CM (2007) Projected number of people with Parkinson disease in the most populous nations, 2005 through 2030. Neurology, 68, 384-386.

[2] Braak H, Del Tredici K, Braak H, \& Del Tredici K (2008) Cortico-basal ganglia-cortical circuitry in Parkinson's disease reconsidered. Experimental Neurology, 212, 226-229.

[3] Braak H, Del Tredici K, Rub U, de Vos RAI, Jansen Steur ENH, \& BraakE (2003) Staging of brain pathology related to sporadic Parkinson's disease. Neurobiol Aging, 24, 197-211.

[4] Hughes A, Daniel S, Kilford L, \& Lees A (1992) Accuracy of clinical diagnosis of idiopathic Parkinson's disease: A clinico-pathological study of 100 cases. J Neurol Neurosurg Psychiatry, 55, 181-184.

[5] Jankovic J (2008) Parkinson's disease: Clinical features and diagnosis. J Neurol Neurosurg Psychiatry, 79, 368-376. 
[6] Snyder HC, \& Adler CH (2007) The patient with Parkinson's disease: Part II - Treating the nonmotor symptoms. J Am Acad Nurse Pract, 19, 189-197.

[7] Broen MPG, Braaksma MM, Patijn J, \& Weber WEJ (2012) Prevalence of pain in Parkinson's disease: A systematic review using the modified QUADAS tool. Mov Disord, 27, 480-484.

[8] Negre-Pages L, Regragui W, Bouhassira D, Grandjean H, Rascol O, \& DoPaMi PSG (2008) Chronic pain in Parkinson's disease: The cross-sectional French DoPaMiP survey. Mov Disord, 23, 1361-1369.

[9] Dauvilliers Y (2007) Insomnia in patients with neurodegenerative conditions. Sleep Med, 8(Suppl 4), S27-S34.

[10] Wen H-B, Zhang Z-X, Wang H, Li L, Chen H, Liu Y, Zhang B, \& Xu Q (2012) Epidemiology and clinical phenomenology for Parkinson's disease with pain and fatigue. Parkinsonism Relat Disord, 18(Suppl 1), S222-S225.

[11] Quittenbaum BH, \& Grahn B (2004) Quality of life and pain in Parkinson's disease: A controlled cross-sectional study. Parkinsonism Relat Disord, 10, 129-136.

[12] Rahman S, Griffin HJ, Quinn NP, \& Jahanshahi M (2008) Quality of life in Parkinson's disease: The relative importance of the symptoms. Mov Disord, 23, 1428-1434.

[13] Roh JH, Kim BJ, Jang JH, Seo WK, Lee SH, Kim JH, Oh K, Park KW, Lee DH, \& Koh SB (2009) The relationship of pain and health-related quality of life in Korean patients with Parkinson's disease. Acta Neurol Scand, 119, 397-403.

[14] Winter Y, von Campenhausen S, Arend M, Longo K, Boetzel K, Eggert K, Oertel WH, Dodel R, \& Barone P (2011) Health-related quality of life and its determinants in Parkinson's disease: Results of an Italian cohort study. Parkinsonism Relat Disord, 17, 265-269.

[15] Fil A, Cano-de-la-Cuerda R, Munoz-Hellin E, Vela L, Ramiro-Gonzalez M, \& Fernandez-de-Las-Penas C (2013) Pain in Parkinson disease: A review of the literature. Parkinsonism Relat Disord 19, 285-294.

[16] Wasner G, \& Deuschl G (2012) Pains in Parkinson diseasemany syndromes under one umbrella. Nat Rev Neurol, 8 , 284-294.

[17] Ford B (2010) Pain in Parkinson's disease. Mov Disord, 25(Suppl 1), S98-103.

[18] Perez-Lloret S, Rey MV, Dellapina E, Pellaprat J, BrefelCourbon C, \& Rascol O (2012) Emerging analgesic drugs for Parkinson's disease. Expert Opin Emerg Drugs, 17, 157-171.

[19] Thompson PD, Buchner D, Pina IL, Balady GJ, Williams MA, Marcus BH, Berra K, Blair SN, Costa F, Franklin B, Fletcher GF, Gordon NF, Pate RR, Rodriguez BL, Yancey AK, \& Wenger NK (2003) Exercise and physical activity in the prevention and treatment of atherosclerotic cardiovascular disease: A statement from the Council on Clinical Cardiology (Subcommittee on Exercise, Rehabilitation, and Prevention) and the Council on Nutrition, Physical Activity, and Metabolism (Subcommittee on Physical Activity). Circulation, 107, 3109-3116.

[20] Del Sorbo F, \& Albanese A (2012) Clinical management of pain and fatigue in Parkinson's disease. Parkinsonism Relat Disord, 18(Suppl 1), S233-S236.

[21] Ha AD, \& Jankovic J (2012) Pain in Parkinson's disease. Mov Disord, 27, 485-491.

[22] Sophie M, \& Ford B (2012) Management of pain in Parkinson's disease. CNS Drugs, 26, 937-948.

[23] Keus S, Munneke M, Graziano M, Paltamaa J, Pelosin E, Domingos J, Bruhlmann S, Ramaswamy B, Prins J,
Struiksma C, Rochester L, Nieuwboer A, Bloem B (2014) European Physiotherapy Guideline for Parkinson's Disease. KNGF/ParkinsonNet, the Netherlands.

[24] Treede RD, Jensen TS, Campbell JN, Cruccu G, Dostrovsky JO, Griffin JW, Hansson P, Hughes R, Nurmikko T, \& Serra J (2008) Neuropathic pain: Redefinition and a grading system forclinical and research purposes. Neurology, 70, 1630-1635.

[25] Haanpää M, Attal N, Backonja M, Baron R, Bennett M, Bouhassira D, Cruccu G, Hansson P, Haythornthwaite J, Iannetti GD, Jensen TS, Kauppilam T, Nurmikko TJ, Rice ASC, Rowbotham M, Serra J, Sommer C, H, \& Treede SB, R-D (2011) NeuPSIG guidelines on neuropathic pain assessment. Pain, 152, 14-27.

[26] Smart KM, Blake C, Staines A, \& Doody CM (2012) The discriminative validity of "nociceptive", "peripheral neuropathic" and "central sensitisation" as mechanisms-based classifications of musculoskeletal pain. Clin J Pain, 28, 655-663.

[27] Lim S-Y, Farrell MJ, \& Evans AH (2011) Parkinson's disease and pain-nondopaminergic mechanisms are likely to be important too. Mov Disord, 26, 1353-1354.

[28] Truini A, Frontoni M, \& Cruccu G (2013) Parkinson's disease related pain: A review of recent findings. J Neurol, 260, 330-334.

[29] Conte A, Khan N, Defazio G, Rothwell JC, \& Berardelli A (2013) Pathophysiology of somatosensory abnormalities in Parkinson disease. Nat Rev Neurol, 9, 687-697.

[30] Mattson MP (2014) Interventions that improve body and brain bioenergetics for Parkinson's disease risk reduction and therapy. J Parkinsons Dis, 4, 1-13.

[31] Petzinger GM, Fisher BE, McEwen S, Beeler JA, Walsh JP, \& Jakowec MW (2013) Exercise-enhanced neuroplasticity targeting motor and cognitive circuitry in Parkinson's disease. Lancet Neurol, 12, 716-726.

[32] Frazzitta G, Balbi P, Maestri R, Bertotti G, Boveri N, \& Pezzoli G (2013) The beneficial role of intensive exercise on Parkinson disease progression. Am J Phys Med Rehabil, 92, 523-532.

[33] Pagano RL, Fonoff ET, Dale CS, Ballester G, Teixeira MJ, \& Britto LRG (2012) Motor cortex stimulation inhibits thalamic sensory neurons and enhances activity of PAG neurons: Possible pathways for antinociception. Pain, 153, 2359-2369.

[34] Petzinger GM, Fisher BE, Meshul CK, Walsh JP, Akopian G, Jakowec MW (2011) Effects of exercise on basal ganglia function in Parkinson's disease and its animal models. In Parkinson's Disease: Non-Motor and Non-Dopaminergic Features, Olanow CW, Stocchi F, Lang AE, eds. WileyBlackwell, Chichester, pp. 416-431.

[35] McNeill TH, Brown SA, Rafols JA, \& Shoulson I (1988) Atrophy of medium spiny I striatal dendrites in advanced Parkinson's disease. Brain Res, 455, 148-152.

[36] Stephens B, Mueller AJ, Shering AF, Hood SH, Taggart P, Arbuthnott GW, Bell JE, Kilford L, Kingsbury AE, Daniel SE, \& Ingham CA (2005) Evidence of a breakdown of corticostriatal connections in Parkinson's disease. Neuroscience, 132, 741-754.

[37] Toy WA, Petzinger GM, Leyshon BJ, Akopian GK, Walsh JP, Hoffman MV, Vuckovic MG, \& Jakowec MW (2014) Treadmill exercise reverses dendritic spine loss in direct and indirect striatal medium spiny neurons in the 1-methyl-4phenyl-1,2,3,6-tetrahydropyridine (MPTP) mouse model of Parkinson's disease. Neurobiol Dis, 63, 201-209.

[38] Tan AM, Samad OA, Fischer TZ, Zhao P, Persson AK, \& Waxman SG (2012) Maladaptive dendritic spine remodel- 
ing contributes to diabetic neuropathic pain. J Neurosci, 32, 6795-6807.

[39] Dobkin BH, Firestine A, West M, Saremi K, \& Woods R (2004) Ankle dorsiflexion as an fMRI paradigm to assay motor control for walking during rehabilitation. Neuroimage, 23, 370-381.

[40] Fisher BE, Li Q, Nacca A, Salem GJ, Song J, Yip J, Hui JS, Jakowec MW, \& Petzinger GM (2013) Treadmill exercise elevates striatal dopamine D2 receptor binding potential in patients with early Parkinson's disease. Neuroreport, 24, 509-514.

[41] Johansson BB (2011) Current trends in stroke rehabilitation A review with focus on brain plasticity. Acta Neurol Scand, 123, $147-159$

[42] Sehm B, Taubert M, Conde V, Weise D, Classen J, Dukart J, Draganski B, Villringer A, \& Ragert P (2014) Structural brain plasticity in Parkinson's disease induced by balance training. Neurobiol Aging, 35, 232-239.

[43] Corcos DM, Robichaud JA, David FJ, Leurgans SE, Vaillancourt DE, Poon C, Rafferty MR, Kohrt WM, \& Comella CL (2013) A two-year randomized controlled trial of progressive resistance exercise for Parkinson's disease. Mov Disord, 28, 1230-1240.

[44] Duncan RP, \& Earhart GM (2012) Randomized controlled trial of community-based dancing to modify disease progression in Parkinson disease. Neurorehabil Neural Repair, 26, 132-143.

[45] Ridgel AL, Vitek JL, Alberts JL, Ridgel AL, Vitek JL, \& Alberts JL (2009) Forced, not voluntary, exercise improves motor function in Parkinson's disease patients. Neurorehabil Neural Repair, 23, 600-608.

[46] Fisher BE, Wu AD, Salem GJ, Song J, Lin C-HJ, Yip J, Cen S, Gordon J, Jakowec M, \& Petzinger G (2008) The effect of exercise training in improving motor performance and corticomotor excitability in people with early Parkinson's disease. Arch Phys Med Rehab, 89, 1221-1229.

[47] Henchcliffe C, \& Severt WL (2011) Disease modification in Parkinson's disease. Drugs Aging, 28, 605-615.

[48] Antoniades CA, \& Barker RA (2008) The search for biomarkers in Parkinson's disease: A critical review. Expert Rev Neurother, 8, 1841-1852.

[49] Chudler EH, \& Dong WK (1995) The role of the basal ganglia in nociception and pain. Pain, 60, 3-38.

[50] Larsen MK, Samani A, Madeleine P, Olsen HB, Sogaard K, \& Holtermann A (2009) Short-term effects of implemented high intensity shoulder elevation during computer work. BMC Musucloskelet Disor, 10, 101.

[51] Olanow CW, \& Schapira AHV (2013) Therapeutic prospects for Parkinson disease. Ann Neurol, 74, 337-347.

[52] Blandini F, Porter RH, \& Greenamyre JT (1996) Glutamate and Parkinson's disease. Mol Neurobiol, 12, 73-94.

[53] Morales I, Sabate M, \& Rodriguez M (2013) Striatal glutamate induces retrograde excitotoxicity and neuronal degeneration of intralaminar thalamic nuclei: Their potential relevance for Parkinson's disease. Eur J Neurosci, 38, 2172-2182.

[54] Mensen A, Poryazova R, Schwartz S, \& Khatami R (2014) Humor as a reward mechanism: Event-related potentials in the healthy and diseased brain. PLoS One, 9, e85978.

[55] Barcelo AC, Filippini B, \& Pazo JH (2012) The striatum and pain modulation. Cell Mol Neurobiol, 32, 1-12.

[56] Galbavy W, Safaie E, Rebecchi MJ, \& Puopolo M (2013) Inhibition of tetrodotoxin-resistant sodium current in dorsal root ganglia neurons mediated by D1/D5 dopamine receptors. Mol Pain, 9, 1744-8069.
[57] Bleakman D, Alt A, \& Nisenbaum ES (2006) Glutamate receptors and pain. Semin Cell Dev Biol, 17, 592-604.

[58] Woolf CJ (2011) Central sensitization: Implications for the diagnosis and treatment of pain. Pain, 152, 18.

[59] Fisher BE, Petzinger GM, Nixon K, Hogg E, Bremmer S, Meshul CK, \& Jakowec MW (2004) Exercise-induced behavioral recovery and neuroplasticity in the 1-methyl4-phenyl-1,2,3,6-tetrahydropyridine-lesioned mouse basal ganglia. J Neurosci Res, 77, 378-390.

[60] Hagelberg N, Jaaskelainen SK, Martikainen IK, Mansikka H, Forssell H, Scheinin H, Hietala J, \& Pertovaara A (2004) Striatal dopamine D2 receptors in modulation of pain in humans: A review. Eur J Pharmacol, 500, 187-192.

[61] Calabresi P, Pisani A, Centonze D, \& Bernardi G (1997) Synaptic plasticity and physiological interactions between dopamine and glutamate in the striatum. Neurosci Biobehav Rev, 21, 519-523.

[62] VanLeeuwen J-E, Petzinger GM, Walsh JP, Akopian GK, Vuckovic M, \& Jakowec MW (2010) Altered AMPA receptor expression with treadmill exercise in the 1-methyl4-phenyl-1,2,3,6-tetrahydropyridine-lesioned mouse model of basal ganglia injury. J Neurosci Res, 88, 650-668.

63] Gerdelat-Mas A, Simonetta-Moreau M, Thalamas C, Ory-Magne F, Slaoui T, Rascol O, \& Brefel-Courbon C (2007) Levodopa raises objective pain threshold in Parkinson's disease: A RIII reflex study. J Neurol Neurosurg Psychiatry, 78, 1140-1142.

[64] Brefel-Courbon C, Payoux P, Thalamas C, Ory F, Quelven I, Chollet F, Montastruc JL, \& Rascol O (2005) Effect of levodopa on pain threshold in Parkinson's disease: A clinical and positron emission tomography study. Mov Disord, 20, 1557-1563.

[65] Djaldetti R, Shifrin A, Rogowski Z, Sprecher E, Melamed E, \& Yarnitsky D (2004) Quantitative measurement of pain sensation in patients with Parkinson disease. Neurology, 62, 2171-2175.

[66] Granovsky Y, Schlesinger I, Fadel S, Erikh I, Sprecher E, \& Yarnitsky D (2013) Asymmetric pain processing in Parkinson's disease. Eur J Neurol, 20, 1375-1382.

[67] Tinazzi M, Del Vesco C, Fincati E, Ottaviani S, Smania N, Moretto G, Fiaschi A, Martino D, \& Defazio G (2006) Pain and motor complications in Parkinson's disease. $J$ Neurol Neurosurg Psychiatry, 77, 822-825.

[68] Scherder E, Wolters E, Polman C, Sergeant J, \& Swaab D (2005) Pain in Parkinson's disease and multiple sclerosis: Its relation to the medial and lateral pain systems. Neurosci Biobehav Rev, 29, 1047-1056.

[69] Koltyn KF (2000) Analgesia following exercise: A review. Sports Med, 29, 85-98.

[70] Smith MA, \& Lyle MA (2006) Chronic exercise decreases sensitivity to mu opioids in female rats: Correlation with exercise output. Pharmacol Biochem Behav, 85, 12-22.

[71] Smith MA, \& Yancey DL (2003) Sensitivity to the effects of opioids in rats with free access to exercise wheels: $\mathrm{Mu}$-opioid tolerance and physical dependence. Psychopharmacology, 168, 426-434.

72] Mazzardo-Martins L, Martins DF, Marcon R, dos Santos UD, Speckhann B, Gadotti VM, Sigwalt AR, Guglielmo LGA, \& Santos ARS (2010) High-intensity extended swimming exercise reduces pain-related behavior in mice: Involvement of endogenous opioids and the serotonergic system. J Pain, 11, 1384-1393.

[73] Martins DF, Mazzardo-Martins L, Soldi F, Stramosk J, Piovezan AP, \& Santos ARS (2013) High-intensity swimming exercise reduces neuropathic pain in an animal model 
of complex regional pain syndrome type I: Evidence for a role of the adenosinergic system. Neuroscience, 234, 69-76.

[74] Heinricher MM, Fields HL (2013) Central nervous system mechanisms of pain modulation. In Wall and Melzack's textbook of pain, McMahon SB, ed. Elsevier/Saunders, Philadelphia, pp. 129-142.

[75] Dworak M, Diel P, Voss S, Hollmann W, \& Struder HK (2007) Intense exercise increases adenosine concentrations in rat brain: Implications for a homeostatic sleep drive. Neuroscience, 150, 789-795.

[76] Roque FR, Soci UP, De Angelis K, Coelho MA, Furstenau CR, Vassallo DV, Irigoyen MC, \& Oliveira EM (2011) Moderate exercise training promotes adaptations in coronary blood flow and adenosine production in normotensive rats. Clinics, 66, 2105-2111.

[77] Hasko G, \& Cronstein B (2013) Regulation of inflammation by adenosine. Front Immunol, $\mathbf{4}, 85$.

[78] Hasko G, Linden J, Cronstein B, \& Pacher P (2008) Adenosine receptors: Therapeutic aspects for inflammatory and immune diseases. Nat Rev Drug Discov, 7, 759-770.

[79] Stagg NJ, Mata HP, Ibrahim MM, Henriksen EJ, Porreca F, Vanderah TW, \& Philip Malan T Jr (2011) Regular exercise reverses sensory hypersensitivity in a rat neuropathic pain model: Role of endogenous opioids. Anesthesiology, 114, 940-948.

[80] Kuphal KE, Fibuch EE, \& Taylor BK (2007) Extended swimming exercise reduces inflammatory and peripheral neuropathic pain in rodents. J Pain, 8, 989-997.

[81] Chiou RJ, Chang CW, \& Kuo CC (2013) Involvement of the periaqueductal gray in the effect of motor cortex stimulation. Brain Res, 15, 28-35.

[82] Bandler R, \& Keay KA (1996) Columnar organization in the midbrain periaqueductal gray and the integration of emotional expression. Prog Brain Res, 107, 285-300.

[83] Pavlovic ZW, Cooper ML, \& Bodnar RJ (1996) Opioid antagonists in the periaqueductal gray inhibit morphine and beta-endorphin analgesia elicited from the amygdala of rats. Brain Res, 741, 13-26.

[84] Allen NE, Sherrington C, Paul SS, \& Canning CG (2011) Balance and falls in Parkinson's disease: A meta-analysis of the effect of exercise and motor training. Mov Disord, 26, 1605-1615.

[85] Goodwin VA, Richards SH, Henley W, Ewings P, Taylor AH, \& Campbell AJ (2011) An exercise intervention to prevent falls in people with Parkinson's disease: A pragmatic randomised controlled trial. J Neurol Neurosurg Psychiatry, 82, 1232-1238.

[86] Tomlinson CL, Patel S, Meek C, Herd CP, Clarke CE, Stowe R, Shah L, Sackley C, Deane KHO, Wheatley K, \& Ives N (2012) Physiotherapy intervention in Parkinson's disease: Systematic review and meta-analysis. BMJ, 345, e5004.

[87] Lima LO, Scianni A, \& Rodrigues de Paula F (2013) Progressive resistance exercise improves strength and physical performance in people with mild to moderate Parkinson's disease: A systematic review. J Physiother, 59, 7-13.

[88] Bergen JL, Toole T, Elliott RG, 3rd, Wallace B, Robinson K, Maitland CG, Bergen JL, Toole T, Elliott RG, 3rd, Wallace B, Robinson K, \& Maitland CG (2002) Aerobic exercise intervention improves aerobic capacity and movement initiation in Parkinson's disease patients. Neurorehabilitation, 17, 161-168.

[89] Bridgewater K, \& Sharpe M (1996) Aerobic exercise and early Parkinson's disease. J Neurol Rehabil, 10, 233-241.
[90] Burini D, Farabollini B, Iacucci S, Rimatori C, Riccardi G, Capecci M, Provinciali L, \& Ceravolo MG (2006) A randomised controlled cross-over trial of aerobic training versus Qigong in advanced Parkinson's disease. Eura Medicophys, 42, 231-238.

[91] Ashburn A, Fazakarley L, Ballinger C, Pickering R, McLellan LD, \& Fitton C (2007) A randomised controlled trial of a home-based exercise programme to reduce the risk of falling among people with Parkinson's disease. J Neurol Neurosurg Psychiatry, 78, 678-684.

[92] Li F, Harmer P, Fitzgerald K, Eckstrom E, Stock R, Galver J, Maddalozzo G, \& Batya SS (2012) Tai Chi and postural stability in patients with Parkinson's disease. N Engl J Med, 366, 511-519.

[93] Smania N, Corato E, Tinazzi M, Stanzani C, Fiaschi A, Girardi P, \& Gandolfi M (2010) Effect of balance training on postural instability in patients with idiopathic Parkinson's disease. Neurorehabil Neural Repair, 24, 826-834.

[94] Reuter I, Mehnert S, Leone P, Kaps M, Oechsner M, \& Engelhardt M (2011) Effects of a flexibility and relaxation programme, walking, and nordic walking on Parkinson's disease. J Aging Res 2011, 232473

[95] Rodrigues de Paula F, Teixeira-Salmela LF, Coelho de Morais Faria CD, Rocha de Brito P, Cardoso F, Rodrigues de Paula F, Teixeira-Salmela LF, Coelho de Morais Faria CD, Rocha de Brito P, \& Cardoso F (2006) Impact of an exercise program on physical, emotional, and social aspects of quality of life of individuals with Parkinson's disease. Mov Disord, 21, 1073-1077.

[96] Hagell P, Whalley D, McKenna SP, \& Lindvall O (2003) Health status measurement in Parkinson's disease: Validity of the PDQ-39 and Nottingham Health Profile. Mov Disord, 18, 773-783.

[97] Kay TM, Gross A, Goldsmith CH, Rutherford S, Voth S, Hoving JL, Bronfort G, \& Santaguida PL (2012) Exercises for mechanical neck disorders. Cochrane Database Syst Rev, 15, CD004250.

[98] Hurwitz EL, Carragee EJ, van der Velde G, Carroll LJ, Nordin M, Guzman J, Peloso PM, Holm LW, Cote P, HoggJohnson S, Cassidy JD, \& Haldeman S (2008) Treatment of neck pain: Noninvasive interventions: Results of the Bone and Joint Decade 2000-2010 Task Force on Neck Pain and Its Associated Disorders. Spine, 33, S123-S152.

[99] Hayden JA, van Tulder MW, Malmivaara A, Koes BW (2005) Exercise therapy for treatment of non-specific low back pain. Cochrane Database Syst Rev, CD000335.

[100] Fransen M, McConnell S (2008) Exercise for osteoarthritis of the knee. Cochrane Database Syst Rev, CD004376.

[101] Fransen M, McConnell S, Hernandez-Molina G, Reichenbach S (2009) Exercise for osteoarthritis of the hip. Cochrane Database Syst Rev, CD007912.

[102] Nicholas MK, Molloy A, Tonkin L, Beeston L (2012) Manage your pain: Practical and positive ways of adapting to pain, Souvenir Press, London.

[103] Nijs J, Kosek E, Van Oosterwijck J, \& Meeus M (2012) Dysfunctional endogenous analgesia during exercise in patients with chronic pain: To exercise or not to exercise? Pain Physician, 15, ES205-ES213.

[104] Staud R, Nagel S, Robinson ME, \& Price DD (2009) Enhanced central pain processing of fibromyalgia patients is maintained by muscle afferent input: A randomized, doubleblind, placebo-controlled study. Pain, 145, 96-104.

[105] Van Oosterwijck J, Nijs J, Meeus M, Van Loo M, \& Paul L (2012) Lack of endogenous pain inhibition during exercise 
in people with chronic whiplash associated disorders: An experimental study. J Pain, 13, 242-254.

[106] Nijs J, Meeus M, Van Oosterwijck J, Roussel N, De Kooning M, Ickmans K, \& Matic M (2011) Treatment of central sensitization in patients with 'unexplained' chronic pain: What options do we have? Expert Opin Pharmacother, 12 1087-1098

[107] Mylius V, Engau I, Teepker M, Stiasny-Kolster K, Schepelmann K, Oertel WH, Lautenbacher S, \& Moller JC (2009) Pain sensitivity and descending inhibition of pain in Parkinson's disease. J Neurol Neurosurg Psychiatry, 80, 24-28.
[108] Moseley GL, \& Flor H (2012) Targeting cortical representations in the treatment of chronic pain: A review. Neurorehabil Neural Repair, 26, 646-652.

[109] Boudreau S, Romaniello A, Wang K, Svensson P, Sessle BJ, \& Arendt-Nielsen L (2007) The effects of intra-oral pain on motor cortex neuroplasticity associated with shortterm novel tongue-protrusion training in humans. Pain, 132, 169-178.

[110] Butler D, Moseley GL (2003) Explain Pain, Noigroup, Adelaide. 